\title{
Investment, Capacity, and Output: A Putty-Clay Approach ${ }^{1}$
}

\author{
Simon Gilchrist \\ Department of Economics \\ Boston University \\ 270 Bay State Road \\ Boston, MA 02215 \\ and National Bureau of Economic Research \\ sgilchri@bu.edu \\ and \\ John C. Williams \\ Board of Governors of the Federal Reserve System \\ Mail Stop 67 \\ Washington, DC 20551 \\ jwilliams@frb.gov
}

November 1998

\begin{abstract}
In this paper, we embed the microeconomic decisions associated with investment under uncertainty, capacity utilization, and machine replacement in a general equilibrium model based on putty-clay technology. We show that the combination of log-normally distributed idiosyncratic productivity uncertainty and Leontief utilization choice yields an aggregate production function that is easily characterized in terms of hazard rates for the standard normal distribution. At low levels of idiosyncratic uncertainty, the short-run elasticity of supply is substantially lower than the elasticity of supply obtained from a fully-flexible Cobb-Douglas alternative. In the presence of irreversible factor proportions, an increase in idiosyncratic uncertainty typically reduces investment at the micro level but increases aggregate investment. Finally, we study the relationship between growth and uncertainty on aggregate capacity utilization and rates of machine replacement and investigate the factors that affect the magnitude of replacement echoes.
\end{abstract}

Keywords: putty-clay, vintage capital, irreversibility, machine replacement, capacity utilization, replacement echoes

JEL Classification: D24, E22, E23

\footnotetext{
${ }^{1}$ We appreciate the research assistance provided by Steven Sumner and Joanna Wares and wish to thank Flint Brayton, Jeff Campbell, Thomas Cooley, Russell Cooper, Sam Kortum, and John Leahy for helpful comments. The opinions expressed here are not necessarily shared by the Board of Governors of the Federal Reserve System or its staff.
} 


\section{Introduction}

A large body of research in macroeconomics, growth accounting, and production theory is predicated on a Cobb-Douglas production function and a capital accumulation process with exponential decay. This production structure is consistent with the empirical observation that labor's share of output is approximately constant in the long run despite steady declines in the relative price of investment goods. Although the Cobb-Douglas specification is able to deliver observed long-run balanced-growth relationships, it is not well-suited to describe short-run production possibilities in the context of heterogeneous capital goods. In particular, a key assumption needed to achieve aggregation in this framework is that labor is equally flexible in both the short and long run. Such flexibility allows marginal products of labor to be equalized across capital goods. It also implies, in the absence of modifications such as costs of operating capital, that all capital goods are used in production and that the short-run elasticity of supply is constant and is a function only of the long-run labor share of income.

In this paper, we develop an alternative description of production and capital accumulation that is based on the putty-clay technology introduced by Johansen (1959). The ex ante production technology is Cobb-Douglas, but for installed capital, the technology is Leontief with productivity determined by the initial choice of capital intensity. We develop a general equilibrium model where aggregate relationships are explicitly derived from the microeconomic decisions of investment, capacity choice, and production. By adopting the putty-clay specification of technology, we relax many of the constraints imposed by a Cobb-Douglas production structure while preserving its desirable long-run properties. This approach provides a natural framework for the study of a wide range of issues including the relationship between production and capacity utilization, the decision to invest under uncertainty, and the implications of technological change for capital obsolescence and machine replacement. ${ }^{2}$

Aggregation from microeconomic decisions to macroeconomic variables is a key issue for models with heterogeneous capital goods. We show that under the assump-

\footnotetext{
${ }^{2}$ Putty-clay models have a long history in both the growth (Johansen (1959), Solow (1962), Phelps (1963), Cass and Stiglitz (1969), Sheshinski (1967), and Calvo (1976)) and investment literatures (Bischoff (1971) and Ando, Modigliani, Rasche and Turnovsky (1974)). Putty-clay features are also found in more recent work on business cycles (Atkeson and Kehoe (1994), Benhabib and Rustichini (1991), and Benhabib and Rustichini (1993)).
} 
tion of log-normally distributed idiosyncratic productivity, there exists a well-defined aggregate production function with a short-run elasticity of output with respect to labor strictly less than that of the Cobb-Douglas alternative. This result provides a stark contrast to Houthakker (1953), who finds that a Leontief microeconomic structure aggregates to a Cobb-Douglas production function if the distribution of idiosyncratic uncertainty is Pareto. We focus on the log-normal distribution because its use facilitates the analysis of aggregate quantities while preserving the putty-clay characteristics of the microeconomic structure. A key advantage of this framework is that all relevant elasticities of production are functions of hazard rates for a standard normal distribution, the properties of which can be exploited in deriving analytical results.

We also consider the relationship between investment and uncertainty in both partial and general equilibrium. The partial equilibrium analysis focuses on the intensive margin where the decision is how much to invest per project, while the general equilibrium analysis takes into account movements in relative prices and investment on the extensive margin that occurs through new entry. We find that an increase in idiosyncratic uncertainty reduces investment at the project level but raises investment in the aggregate. The former result is broadly consistent with the empirical evidence of a negative relationship between investment and uncertainty at the firm-level (Leahy and Whited 1996).

Our analysis contributes to the large theoretical literature that identifies channels through which uncertainty may influence investment. Bernanke (1983) and Pindyck (1991) stress the negative influence that uncertainty has in a model where there exists an "option value" to waiting to invest. Because the uncertainty considered in this paper is resolved only after investment decisions are made, our work is more directly related to the work of Hartman (1972) and Abel (1983). These authors emphasize the positive effect that increased uncertainty may have on firm-level investment because expected profits increase with uncertainty. In our framework, increased uncertainty raises expected profits but reduces the expected marginal return to capital, causing a reduction in capital intensity at the microeconomic level.

The increase in aggregate investment is a natural consequence of the reallocation benefits associated with redistributing variable factors of production, such as labor, across project outcomes that are embodied in fixed factors, such as capital. When compared to the benchmark vintage capital model introduced by Solow (1962), we 
show that the additional irreversiblity of the capital-labor ratio associated with the putty-clay framework limits such reallocation benefits. As a result, the expansionary effects of increased uncertainty are lower in the putty-clay model vis-a-vis the puttyputty alternative.

Finally, we consider the relationship between embodied technological change, capital obsolescence, and machine replacement along a balanced growth path. Of particular interest is the relationship between uncertainty and machine retirement: with low variability in productivity outcomes machine retirement is entirely a function of machine age, and depreciation is "one-hoss-shay"; as the variance of project outcomes increases, machine age and machine retirement become less correlated and depreciation schedules begin to resemble exponential decay. This analysis complements the literature on the effects of technological lock-in that motivate the machine replacement problem first addressed by Johansen (1959) and Calvo (1976), and more recently formalized in a dynamic programming environment by Cooper and Haltiwanger (1993) and Cooley, Greenwood and Yorukoglu (1994). We also consider the factors that contribute to replacement echoes of the type studied by Boucekkine, Germain and Licandro (1997). We show that two factors are essential to the presence of replacement echoes: a high intertemporal elasticity of substitution of consumption and a low degree of idiosyncratic uncertainty of investment productivity.

The remainder of this paper is divided as follows: Section 2 presents a description of the model and equilibrium conditions. Section 3 shows the equilibrium determination of utilization rates within the analytically tractable case of the no-growth economy and provides closed-form expressions for all economic variables as functions of the equilibrium utilization rate. Section 4 considers the effect of increased uncertainty on investment at both the project level and in the aggregate, and section 5 extends the analysis to an economy with positive growth.

\section{The Model}

In this section, we describe the putty-clay model and derive the equilibrium conditions. Each capital good possesses two defining qualities: its level of embodied technology and its capital intensity. The underlying ex ante production technology is assumed to be Cobb-Douglas with constant returns to scale, but for capital goods in place, production possibilities take the Leontief form: there is no ex post substitutability of capital and labor at the microeconomic level. In addition to ag- 
gregate technological change, we allow for the existence of idiosyncratic uncertainty regarding the productivity of investment projects. To characterize the equilibrium allocation, we first discuss the optimization problem at the project level and then describe aggregation from the project level to the aggregate allocation. ${ }^{3}$

\subsection{The Investment Decision}

Each period, a set of new investment "projects" becomes available. Constant returns to scale implies an indeterminacy of scale at the level of projects, so without loss of generality, we normalize all projects to employ one unit of labor at full capacity. We refer to these projects as "machines." Capital goods require one period for initial installation and then are productive for $1 \leq M \leq \infty$ periods. The productive efficiency of machine $i$ initiated at time $t$ is affected by a random idiosyncratic productivity term. In addition, we assume all machines, regardless of their relative efficiency, fail at an exogenously given rate that varies by the age of the machine. In summary, capital goods are heterogeneous and are characterized by three attributes: vintage (age and level of aggregate embodied technology), capital-intensity, and the realized value of the idiosyncratic productivity term.

The productivity of each machine, initiated at time $t$, differs according to the log-normally distributed random variable, $\theta_{i, t}$, where

$$
\ln \theta_{i, t} \sim N\left(\ln \theta_{t}-\frac{1}{2} \sigma^{2}, \sigma^{2}\right) .
$$

The aggregate index $\theta_{t}$ measures the mean level of embodied technology of vintage $t$ investment goods and $\sigma^{2}$ is the variance of the idiosyncratic shock. The mean correction term $-\frac{1}{2} \sigma^{2}$ implies $E\left(\theta_{i, t} \mid \theta_{t}\right)=\theta_{t}$. We assume $\theta_{t}$ follows a non-stochastic trend growth process with gross growth rate $(1+g)^{1-\alpha}$.

The idiosyncratic shock to individual machines is not observed until after the investment decisions are made. We also assume that after the revelation of the idiosyncratic shock, further investments in existing machines are not possible. Subject to the constraint that labor employed, $L_{i, t+j}$, is nonnegative and less than or equal to unity (capacity), final goods output produced in period $t+j$ by machine $i$ of vintage $t$ is

$$
Y_{i, t+j}=\theta_{i, t} k_{i, t}^{\alpha} L_{i, t+j},
$$

\footnotetext{
${ }^{3}$ This section closely follows Gilchrist and Williams (1998).
} 
Figure 1: Steady-state Distribution of Labor Productivity

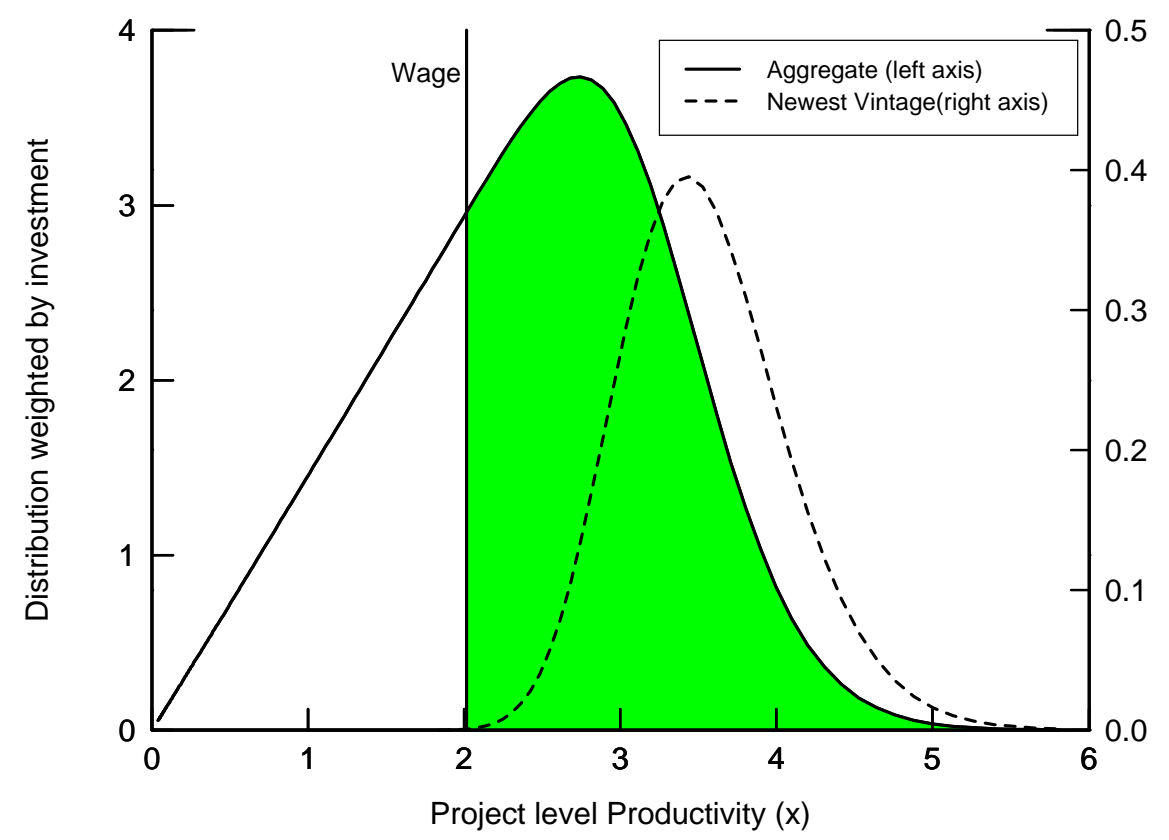

where $k_{i, t}$ is the capital-labor ratio chosen at the time of installation. Denote the labor productivity of a machine by

$$
X_{i, t} \equiv \theta_{i, t} k_{i, t}^{\alpha}
$$

The only variable cost to operating a machine is the wage rate, $W_{t}$. Idle machines incur no variable costs and have the same capital costs as operating machines. Given the Leontief structure of production, these assumptions imply a cutoff value for the minimum efficiency level of machines used in production: those with productivity $X_{i, t} \geq W_{t}$ are run at capacity, while those less productive are left idle.

To illustrate these ideas, Figure 1 shows the steady-state distribution of labor productivity across machines. The height of the distribution measures the number of machines at any given productivity level. The cutoff value for the wage is shown as a vertical line. Capital goods with productivity lying to the right of the cutoff are used in production, those to the left are idle. Capacity utilization is given by the area in the shaded region divided by the total area under the distribution.

The figure also shows the distribution of labor productivity for the most recent vintage (right scale). Its position on the horizonal axis reflects both the current level 
of technology and the capital intensity of new machines. Owing to trend productivity growth and relatively long-lived capital, the mean labor productivity of the most recent vintage is substantially higher than that of all existing machines. Obsolescence through embodied technical change implies that old vintages have lower average utilization rates than new vintages. Note that trend growth in investment-due to population growth and technological change - causes the aggregate distribution to be skewed.

To derive the equilibrium allocation of labor, capital intensity, and investment, we begin by analyzing the investment and utilization decision for a single machine. Define the time $t$ discount rate for time $t+j$ income by $\tilde{R}_{t, t+j} \equiv \prod_{s=1}^{j} R_{t+s}^{-1}$, where $R_{t+s}$ is the one period gross interest rate at time $t+s$. At the machine level, capital intensity is chosen to maximize the present discounted value of profits to the machine

$$
\begin{aligned}
\max _{k_{i, t},\left\{L_{i, t+j}\right\}_{j=1}^{M}} E\left\{-k_{i, t}+\sum_{j=1}^{M} \tilde{R}_{t, t+j}\left(1-\delta_{j}\right)\left(X_{i, t}-W_{t+j}\right) L_{i, t+j}\right\}, \\
\text { s.t. } \quad 0 \leq L_{i, t+j} \leq 1, \quad j=1, \ldots, M, \\
0<k_{i, t}<\infty
\end{aligned}
$$

where $\delta_{j}$ is the probability a machine has failed exogenously by $j$ periods and expectations are taken over the time $t$ idiosyncratic shock, $\theta_{i, t}$.

Because investment projects are identical ex ante, the optimal choice of the capital-labor ratio is equal across all machines in a vintage; that is, $k_{i, t}=k_{t}, \forall i$. Denote the mean productivity of vintage $t$ capital by $X_{t}=\theta_{t} k_{t}^{\alpha}$. Capital utilization for vintage $s$ at time $t$ is the ratio of labor employed to employment capacity of the vintage, given by $\operatorname{Pr}\left(X_{i, s}>W_{t} \mid W_{t}, \theta_{t}\right)$. Given the log-normal distribution for $\theta_{i, t}$, the expected labor requirement at time $t$ for a machine built in period $\mathrm{s}$ is given by

$$
\operatorname{Pr}\left(X_{i, s}>W_{t} \mid W_{t}, \theta_{t}\right)=1-\Phi\left(z_{t}^{s}\right)
$$

where $\Phi(\cdot)$ is the c.d.f. of the standard normal and

$$
z_{t}^{s} \equiv \frac{1}{\sigma}\left(\ln W_{t}-\ln X_{s}+\frac{1}{2} \sigma^{2}\right)
$$

Letting $F\left(X_{i, s}\right)$ denote the c.d.f. of $X_{i, s}$, we can similarly compute expected output to be

$$
\int_{X_{i, s}>W_{t}}^{\infty} X_{i, s} d F\left(X_{i, s}\right)=\left(1-\Phi\left(z_{t}^{s}-\sigma\right)\right) X_{s}
$$


where the expression on the right hand side follows from the formula for the expectation of a truncated log-normal random variable. ${ }^{4}$ Capacity utilization of vintage $s$ capital at time $t$ - the ratio of actual output produced from the capital of a given vintage to the level of output that could be produced at full capital utilization - equals $\left(1-\Phi\left(z_{t}^{s}-\sigma\right)\right)$.

Expected net income in period $t$ from a vintage $s$ machine, $\pi_{t}^{s}$, conditional on $W_{t}$, is given by

$$
\pi_{t}^{s}=\left(1-\delta_{t-s}\right)\left(\left(1-\Phi\left(z_{t}^{s}-\sigma\right)\right) X_{s}-\left(1-\Phi\left(z_{t}^{s}\right)\right) W_{t}\right)
$$

Substituting this expression for net income into equation 1 eliminates the future choices of labor from the investment problem. The remaining choice variable is $k_{t}$.

The choice of $k_{t}$ has a direct effect on profitability through its effect on the expected value of output $X_{t}$. It also has a potential indirect effect through its influence on utilization rates. For any given realization of $\theta_{i t}$, a higher choice of $k_{t}$ raises the probability that a machine will be utilized in the future. This increase in utilization raises both expected future output and expected future wage payments. Because the marginal machine earns zero quasi-rents, this indirect effect has no marginal effect on profitability however, that is,

$$
\frac{\partial \pi_{t}^{s}}{\partial z_{t}^{s}}=\frac{1}{\sigma} \phi\left(z_{t}^{s}-\sigma\right) X_{s}-\frac{1}{\sigma} \phi\left(z_{t}^{s}\right) W_{t}=0,
$$

where $\phi(\cdot)$ denotes the p.d.f. for a standard normal random variable. The first-order condition for an interior solution for $k_{t}$ is given by

$$
k_{t}=\alpha \sum_{j=1}^{M} \tilde{R}_{t, t+j}\left(1-\delta_{j}\right)\left(1-\Phi\left(z_{t+j}^{t}-\sigma\right)\right) X_{t} .
$$

New machines are put into place until the value of a new machine (the present discounted value of net income) is equal to the cost of a machine, $k_{t}$,

$$
k_{t}=\sum_{j=1}^{M} \tilde{R}_{t, t+j}\left(1-\delta_{j}\right)\left(\left(1-\Phi\left(z_{t+j}^{t}-\sigma\right)\right) X_{t}-\left(1-\Phi\left(z_{t+j}^{t}\right)\right) W_{t+j}\right) .
$$

This is the free-entry or zero-profit condition. The first term on the right hand side of equation 3 equals the expected present discounted value of output adjusted for the probability that the machine's idiosyncratic productivity draw is too low to

\footnotetext{
${ }^{4}$ If $\ln (\mu) \sim N\left(\zeta, \sigma^{2}\right)$, then $E(\mu \mid \mu>\chi)=\frac{(1-\Phi(\gamma-\sigma))}{(1-\Phi(\gamma))} E(\mu)$ where $\gamma=(\ln (\chi)-\zeta) / \sigma$ (Johnson, Kotz and Balakrishnan 1994).
} 
profitably operate the machine in period $t+j$. The second term equals the expected present value of the wage bill, adjusted for the probability of such a shutdown. Equations 2 and 3 jointly imply that, in equilibrium, the expected present value of the wage bill equals $(1-\alpha)$ times the expected present value of revenue.

\subsection{Aggregation}

Total labor employment, $L_{t}$, is equal to the sum of employment from all existing vintages of capital

$$
L_{t}=\sum_{j=1}^{M}\left(1-\Phi\left(z_{t}^{t-j}\right)\right)\left(1-\delta_{j}\right) Q_{t-j},
$$

where $Q_{t-j}$ is the quantity of new machines started in period $t-j$. Aggregate final output, $Y_{t}$, is

$$
Y_{t}=\sum_{j=1}^{M}\left(1-\Phi\left(z_{t}^{t-j}-\sigma\right)\right)\left(1-\delta_{j}\right) Q_{t-j} X_{t-j} .
$$

In the absence of government spending or other uses of output, aggregate consumption, $C_{t}$, satisfies

$$
C_{t}=Y_{t}-k_{t} Q_{t},
$$

where $k_{t} Q_{t}$ is gross investment in new machines.

\subsection{Preferences}

The economy is made up of representative households whose preferences are given by

$$
\frac{1}{1-\gamma} \sum_{s=0}^{\infty} \beta^{s}\left(\frac{C_{t+s}\left(N_{t+s}-L_{t+s}\right)^{\psi}}{N_{t+s}}\right)^{1-\gamma},
$$

where $\beta \in(0,1), \psi>0,1 / \gamma>0$ is the intertemporal elasticity of substitution, and $N_{t}=N_{0}(1+n)^{t}$ is the household's growing time endowment. Households optimize over these preferences subject to the standard intertemporal budget constraint. We assume that claims on the profits streams of individual machines are traded; in equilibrium, households own a diversified portfolio of all such claims.

The first-order condition with respect to consumption is given by

$$
U_{c, t}=\frac{\beta}{1+n} R_{t, t+1} U_{c, t+1},
$$

where $U_{c, t+s}$ denotes the marginal utility of consumption. The first-order condition with respect to leisure/work is given by

$$
U_{c, t} W_{t}+U_{L, t}=0
$$


where $U_{L, t}$ denotes the marginal utility associated with an incremental increase in work (decrease in leisure).

\subsection{The Solow Vintage Model}

By relaxing the restriction that ex post capital-labor ratios are fixed, the model described above collapses to the neoclassical vintage capital model initially introduced by Solow (1962). For the Solow vintage model, define the capital aggregator, $K_{t}$, by

$$
K_{t} \equiv \sum_{j=1}^{M} \theta_{t-j}^{1 / \alpha}\left(1-\delta_{j}\right) I_{t-j},
$$

where $I_{t}$ denotes gross aggregate capital investment. Aggregate production in period $t$ is given by

$$
Y_{t}=A^{1-\alpha} K_{t}^{\alpha} L_{t}^{1-\alpha},
$$

where $L_{t}$ denotes aggregate labor input and $A=\exp \left(\frac{\sigma^{2}}{2 \alpha}\right)$ is a scale correction that results from aggregating across machines with differing levels of idiosycratic productivity. In this economy, a mean-preserving spread to idiosyncratic productivity causes an increase in disembodied productivity at the aggregate level. If we assume that $\delta_{j}=1-(1-\delta)^{j-1}$ and $M=\infty$, we obtain the following capital accumulation equation

$$
K_{t}=(1-\delta) K_{t-1}+\theta_{t-1}^{1 / \alpha} I_{t-1} .
$$

In the neoclassical vintage model, embodied technological change enters the model through the capital accumulation equation and is equivalent to a reduction in the economic cost of new capital goods.

\section{The No-Growth Economy}

In this section, we derive the conditions describing the steady state of the putty-clay economy with no technological or population growth; the case of positive growth is taken up in section 5 . We first prove the uniqueness of the steady-state equilibrium utilization rate. We then derive closed-form solutions for the steady-state values of all variables as functions of the steady-state utilization rate. In so doing, we show that the model has a well-defined aggregate production function and characterize its properties.

The no-growth economy is obtained by setting $g=n=0$. For further simplicity, we assume $M=\infty$ and $\delta_{j}=1-(1-\delta)^{j-1}$ for some depreciation rate $\delta>0$. Letting 
lower case letters denote steady-state per capita quantities and suppressing time subscripts we define $z=(1 / \sigma)\left[\ln (w)-\ln \left(\theta k^{\alpha}\right)+\frac{1}{2} \sigma^{2}\right]$. Equation 4 then implies that steady-state labor equals the steady-state capital utilization rate times the total stock of machines, $q / \delta$,

$$
l=(1-\Phi(z))(q / \delta)
$$

while equation 5 implies that steady-state output is equal to the steady-state capacity utilization rate times potental output

$$
y=(1-\Phi(z-\sigma)) \theta k^{\alpha}(q / \delta)
$$

For a given capital-labor ratio and stock of machines, labor and output are increasing in the rate of utilization.

Equations 12 and 13 provide an implicit relationship between labor and output that may be interpreted as the short-run production function for this economy (holding capital fixed). Computing the ratio of these two equations, we obtain an expression for the average product of labor (APL)

$$
A P L=\frac{(1-\Phi(z-\sigma))}{(1-\Phi(z))} \theta k^{\alpha} .
$$

Average labor productivity depends on overall machine efficiency $\theta k^{\alpha}$ adjusted for both the rates of capacity utilization and capital utilization. Taking the ratio of partial derivatives, $\frac{\partial y}{\partial z} / \frac{\partial l}{\partial z}$, we obtain an expression for the marginal product of labor (MPL)

$$
M P L=\frac{\phi(z-\sigma)}{\phi(z)} \theta k^{\alpha} .
$$

Taking second derivatives we obtain $\frac{\partial M P L}{\partial l}=-\sigma M P L$, which implies strict concavity of the short-run production function.

Letting $(1 / w)$ denote the relative output price, we can obtain the short-run elasticity of supply by taking logs and then differentiating equation 13 with respect to $\ln w$

$$
\frac{\partial \ln y}{\partial \ln (1 / w)}=\frac{h(z-\sigma)}{\sigma}
$$

where $h(x) \equiv \phi(x) /(1-\Phi(x))$, the hazard rate for the standard normal. In the short run, an expansion of output is achieved through the utilization of marginal machines. The hazard rate $h(z-\sigma)$ measures machine efficiency for machines in use, relative to overall machine efficiency. As output increases, the efficiency of machines in use falls, and the elasticity of supply falls. 
The elasticity of output with respect to labor is computed as the ratio of marginal to average labor productivity; equivalently, it may be expressed in terms of hazard rates

$$
\frac{\partial \ln y}{\partial \ln l}=\frac{h(z-\sigma)}{h(z)} .
$$

This ratio plays a key role in determining both the equilibrium rate of capital utilization.

Combining equations 2, 12, and 13 and solving for the capital-labor ratio per machine yields

$$
k=\left(\frac{\alpha}{r+\delta}(1-\Phi(z-\sigma)) \theta\right)^{\frac{1}{1-\alpha}},
$$

where $r=1 / \beta-1$ is the steady-state equilibrium real interest rate. Except for the adjustment for capacity utilization $(1-\Phi(z-\sigma))$, this is the standard expression for the steady-state capital-labor ratio in a no-growth economy. The adjustment factor implies that the optimal capital-labor ratio for new machines is increasing in the capacity utilization rate.

In equilibrium, the wage rate equals the marginal product of labor, or, equivalently, the efficiency level of the marginal machine. The first-order condition for the labor-leisure decision, equation 9 , and the aggregate resource constraint, equation 6 , yield

$$
\begin{aligned}
w & =\psi \frac{c}{1-l}, \\
c & =y-k q .
\end{aligned}
$$

To close the model and solve for the equilibrium rate of capital utilization, we first express the zero-profit condition as a monotonic function of $z$. In steady state, per-period profits (net of capital expenditures) are given by

$$
\Pi=(1-\Phi(z-\sigma)) \theta k^{\alpha}-(1-\Phi(z)) w-(r+\delta) k,
$$

where $(r+\delta) k$ equals per-period capital expenditures. Using equation 14, we may alternatively express per-period capital expenditures by $\alpha(1-\Phi(z-\sigma)) \theta k^{\alpha}$. Net profits may then be written

$$
\Pi=(1-\Phi(z))\left[(1-\alpha) \frac{y}{l}-w\right] .
$$

The free-entry condition requires that expected net profits equal zero, so that, in equilibrium, labor's share of output equals the wage bill: $(1-\alpha) y=w l$, just 
as in the neoclassical vintage model with Cobb-Douglas production. In the vintage model, this equality is achieved by allocating more labor to high-efficiency machines and less to low-efficiency machines so that the marginal product of labor is equal across machines. Each factor (labor and capital) is paid its share of output so that net profits are zero. In the putty-clay model, marginal products are not equalized across individual machines. Instead, a worker employed on a highly efficient machine is more productive than one employed on a low efficiency machine. Free entry of new machines then determines the utilization rate consistent with zero equilibrium net profits.

To see the link between free entry and utilization, we use the equilibrium condition that the wage rate equals the productivity of the marginal machine to obtain

$$
\frac{w l}{y}=\frac{h(z-\sigma)}{h(z)} .
$$

Free entry requires that the ratio of marginal to average machine efficiencies equals labor's share $(1-\alpha)$. This equilibrium condition determines the steady-state value of $z$ and thereby the steady-state capital utilization rate $(1-\Phi(z))$. We state this result in the following proposition.

Proposition 1 For the no-growth economy, there exists a unique equilibrium value of $z$ that satisfies:

$$
1-\alpha=\frac{h(z-\sigma)}{h(z)}
$$

where $h(x)=\phi(x) /(1-\Phi(x))$ is the hazard rate for the standard normal.

Proof: As shown in the appendix, for any given $\sigma>0, h(z-\sigma) / h(z)$ is monotonically increasing with $\lim _{z \rightarrow-\infty} \frac{h(z-\sigma)}{h(z)}=0$ and $\lim _{z \rightarrow+\infty} \frac{h(z-\sigma)}{h(z)}=1$. Hence, there is a single value of $z$ that satisfies equation 18.

To complete the description of the model, we combine equations 13, 14, 15, and 16 and use the free entry condition to solve for steady-state labor

$$
l=\frac{(1-\alpha)}{1-\alpha-\psi(1-\alpha \delta /(r+\delta))} .
$$

Note that steady-state labor is independent of $z$ and $\sigma^{2}$, the variance of idiosyncratic shocks. As in the case of the Solow vintage model, a mean-preserving spread to idiosyncratic productivity acts like an aggregate disembodied productivity shock with respect to the labor allocation decision and thus has no effect on steady-state 
Figure 2: Equilibrium Utilization Rate

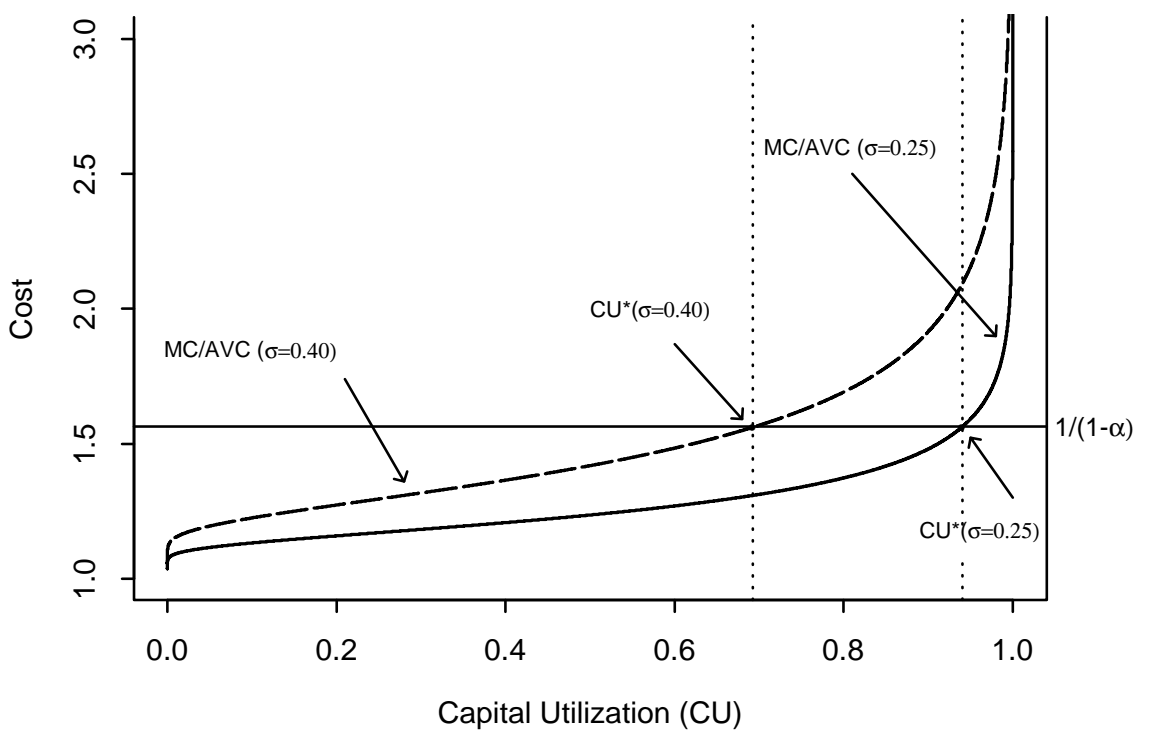

labor. Equilibrium values for all remaining aggregate variables are then computed from $z$ and $l$.

Figure 2 provides a graphical depiction of the steady-state equilibrium. In this figure, we normalize $\theta k^{\alpha}$ at unity and plot the ratio of marginal to average variable cost (the inverse of MPL/APL) as a function of capital utilization for two values of $\sigma$, 0.25 and 0.4. At low levels of utilization, the marginal machine is highly productive and marginal cost is low. At high levels of utilization, the marginal machine is relatively unproductive, and small increases in utilization cause sharp increases in marginal cost. Average variable cost is concave and increasing in utilization with average variable cost equaling unity at full capacity utilization. Because the ratio of marginal to average variable cost is strictly increasing and asymptotes to infinity as the economy approaches full capacity utilization, we are guaranteed a unique equilibrium rate of capital utilization.

The steady-state equilibrium condition that $\frac{M C}{A V C}=\frac{1}{1-\alpha}$ is satisfied for the two cases of $\sigma$ at the points labeled $\mathrm{CU}^{*}$ shown in the figure. If capacity utilization exceeds the equilibrium level, marginal cost is high relative to average variable cost, implying that wages are low relative to labor productivity and profits are positive. Positive profits induce new entry into the market which in turn increases the demand for labor. Given the steady-state quantity of labor, new entry causes wages to rise. Marginal machines are shut down, capacity utilization falls, and profits decline to 
Figure 3: Aggregate Supply Curve

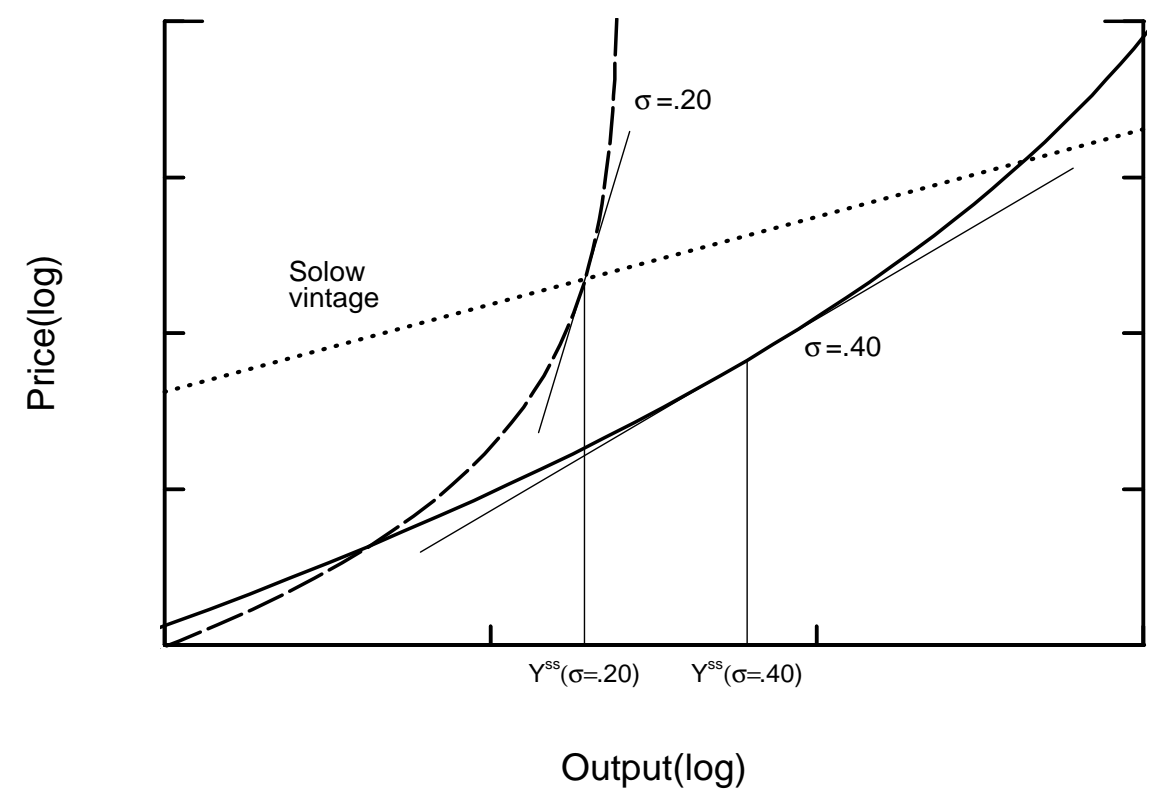

the point that new machines earn zero profits.

The steeply rising $\frac{M C}{A V C}$ curve shown in figure 2 translates into a short-run aggregate supply curve with more curvature than that of the neoclassical vintage model, for which the ratio of $\frac{M C}{A V C}$ is constant and equal to $\frac{1}{1-\alpha}$. To see this more directly, figure 3 plots the $\log$ of output versus the $\log$ of the relative output price $1 / w$ for two specifications of $\sigma$ of the putty-clay model and for the Solow vintage model. In each case, the stock of capital goods is held fixed at its steady-state level. Each curve traces out the increases in output obtained through increases in labor input, i.e., increased utilization in the putty-clay model, in response to higher output prices. In log-terms, the slope of the supply curve is equal to the inverse of the elasticity of supply. In the Solow vintage model, the elasticity of supply is constant and equal to $\frac{1-\alpha}{\alpha}$ and therefore the supply curve is log-linear. In the putty-clay model, the elasticity of supply $\left(\frac{h(z-\sigma)}{\sigma}\right)$ is decreasing in utilization, implying that the slope of the supply curve increases as output increases. As can be seen from figure 3 , for any given $\sigma$, the slope of the supply curve is increasing at an increasing rate as lower and lower quality machines are brought on line.

We expect that increased idiosyncratic uncertainty produces a more flexible economy which translates into a higher elasticity of supply and therefore a flatter supply curve. As can be seen from the tangency lines in figure 3, at the steady-state equilib- 
rium, the slope of the short-run aggregate supply curve is indeed negatively related to the degree of idiosyncratic uncertainty. At the steady-state equilibrium, it is always greater than $\frac{\alpha}{1-\alpha}$, the slope for the Solow vintage model. These results are formalized in the following proposition.

Proposition 2 For the no-growth putty-clay economy, the slope of the aggregate supply curve holding capital fixed, $\frac{\partial \ln (1 / w)}{\partial \ln y}=\frac{\sigma}{h(z-\sigma)}$, is increasing and convex in $\ln y$. Evaluated at the steady-state equilibrium, the slope of the aggregate supply curve is decreasing in the level of idiosyncratic uncertainty and is bounded below by $\frac{\alpha}{1-\alpha}$, the slope of the supply curve for the Solow vintage model.

Proof: Let $\eta=\frac{\partial \ln y}{\partial \ln (1 / w)}=\frac{h(z-\sigma)}{\sigma}$ denote the elasticity of supply. From Result 1 in the appendix, we know that $h(z)$ is log-concave which implies $h(z-\sigma)-(z-\sigma)>$ $h(z)-z$ and $h^{\prime}(z-\sigma)<1$. Using $h^{\prime}(z)=h(z)(h(z)-z)$, and taking partial derivatives, we have: $\frac{\partial \eta}{\partial \ln y}=-\left(\frac{h(z-\sigma)-(z-\sigma)}{\sigma}\right)<0$ and $\frac{\partial^{2} \eta}{\partial(\ln y)^{2}}=\frac{\left(h^{\prime}(z-\sigma)-1\right)}{\sigma h(z-\sigma)}<0$ implying that the slope of the supply curve, $\eta^{-1}$, is increasing and convex in $\ln (y)$. To show $\eta^{-1}$ is decreasing in $\sigma$, we note that in equilibrium $\eta=\frac{(1-\alpha) h(z)}{\sigma}$. Taking derivatives we obtain

$$
\frac{d \eta}{d \sigma}=\left(\frac{h^{\prime}(z)}{h(z)} \frac{d z}{d \sigma}-\frac{1}{\sigma}\right) \eta
$$

and totally differentiating equation 18 we obtain $\frac{d z}{d \sigma}=\frac{h(z-\sigma)-(z-\sigma)}{h(z-\sigma)-h(z)+\sigma}>1$ where the inequality again follows from log-concavity of $h(z)$. Combining these expressions we have

$$
\frac{d \eta}{d \sigma}=\left[\frac{(h(z-\sigma)-(z-\sigma))(h(z)-z)}{h(z-\sigma)-h(z)+\sigma}-\frac{1}{\sigma}\right] \eta .
$$

Result 5 in the appendix relies on convexity of $h(z)$ to show that the term in brackets is strictly positive for any $\sigma>0$. This establishes that $\frac{d \eta}{d \sigma}>0$, and the slope of the supply curve is strictly decreasing in $\sigma$ at the steady-state equilibrium. To establish the lower bound for the slope of the supply curve, in equilibrium, we note that $h(z-\sigma)=(1-\alpha) h(z)$ and $h(z-\sigma)-(z-\sigma)>h(z)-z$ implies $\alpha h(z)<\sigma$ and therefore $\eta=\frac{(1-\alpha) h(z)}{\sigma}<\frac{1-\alpha}{\alpha}$.

In summary, by varying $\sigma$ we vary the slope (and position) of the short-run aggregate supply curve. Thus, the putty-clay aggregate production function effectively embeds, depending on the degree of idiosyncratic uncertainty, the log-linear and relatively flat short-run aggregate supply curve traditionally associated with a 
Cobb-Douglas production structure up to the reverse L-shaped supply curve traditionally associated with the putty-clay framework.

\section{Reallocation Benefits, Investment, and Uncertainty}

We now consider the effect of an increase in idiosyncratic uncertainty on investment at both the project level and the macroeconomic level. We show that increased uncertainty typically reduces investment at the project level but unambiguously increases aggregate investment. The expansionary effect of increased idiosyncratic uncertainty on aggregate investment and output is, however, smaller in the puttyclay model than the neoclassical vintage model owing to the constraint on labor reallocation embedded in the ex post fixity of capital-labor ratios in the putty-clay model.

We start by considering the effect of an increase in $\sigma$ on the steady-state of the putty-clay model. The complete characterization of the effect of an increase in $\sigma$ on the steady-state equilibrium is summarized in the following proposition. ${ }^{5}$

Proposition 3 For the no-growth economy, $\frac{d z}{d \sigma}>1$, and the steady-state capitallabor ratio per machine, $k$, and capacity utilization are strictly decreasing in $\sigma$. Output, consumption, total investment, and the wage rate are increasing in $\sigma$, with semi-elasticity $\frac{d \ln y}{d \sigma}=h(z)$. The investment share is invariant to $\sigma$.

Proof: Equation 18 defines $z$ as an implicit function of $\sigma$ with $\frac{d z}{d \sigma}>1$ following immediately from the increasing hazard property of the standard normal distribution (see the proof of proposition 2). Differentiating the capital-labor ratio $k$ with respect to $\sigma$, and using equation 18 we obtain $\frac{d \ln k}{d \sigma}=-h(z)\left(\frac{d z}{d \sigma}-1\right)<0$. Because steadystate labor is independant of $\sigma$, the flow of new machines is proportional to the inverse of the capital utilization rate. Thus, an increase in $\sigma$ leads to a fall in the steady-state capital utilization rate proportional to the increase in the number of new machines: $\frac{d \ln q}{d \sigma}=h(z) \frac{d z}{d \sigma}>0$. Combining $\frac{d \ln k}{d \sigma}$ with $\frac{d \ln q}{d \sigma}$, we obtain the result that investment $k q$ is increasing in $\sigma: \frac{d \ln (k q)}{d \sigma}=h(z)>0$. Equations 13 and 14 imply that output is linear in investment: $y=\frac{1-\beta(1-\delta)}{\alpha \beta} k q$ so that $\frac{d \ln y}{d \sigma}=h(z)>0$. Thus,

\footnotetext{
${ }^{5}$ In the case of positive growth, we still obtain the result that $\frac{d z}{d \sigma}>1$ and $\frac{d k}{d \sigma}<0$. With growth, however, changes in $\sigma$ influence the effective depreciation rate. As a result, labor is not independant of $\sigma$ and the aggregate output effects are much more difficult to characterize analytically. Numerical results indicate that the variation in $l$ is economically inconsequential and that the results for the no-growth model generalize to the case of positive growth for reasonable choices of $\sigma$.
} 
output and investment rise by the identical $h(z)$ percent in response to a unit increase in $\sigma$, and the investment share of output is invariant to the degree of idiosyncratic uncertainty.

To provide intuition for these results, we first consider the partial equilibrium effect of an increase in $\sigma$ on $k$, holding the wage rate fixed. We then analyze the general equilibrium effect by allowing the wage rate to adjust to its new equilibrium level.

In the putty-clay model, project managers pay $k$ and in effect buy an option to produce in the future. The option is exercised (production occurs) if the ex post realization of revenues exceeds wage costs. ${ }^{6}$ Ceteris paribus, an increase in uncertainty raises the value of the option and increases expected profits. ${ }^{7}$ This is seen in the upper panel of figure 4, which shows expected net profits per machine as a function of $k$, for a given degree of idiosyncratic uncertainty and level of the wage. Holding the wage fixed at $w_{1}$, an increase in $\sigma$ from $\sigma_{1}$ (solid line) to $\sigma_{2}$ (dotted line) raises expected profits per machine for all values of $k$.

In the putty-clay model, the relationship between $k$ and profits - given by equation 17 - combines both the standard concave relationship owing to diminishing returns to capital and the effect of $k$ on expected utilization rates. If $k$ is very high, utilization is nearly $100 \%$ and net profits are approximately equal to $\theta k^{\alpha}-w-(r+\delta) k$, which is strictly concave in $k$. For low values of $k$, however, expected utilization is nearly zero and an incremental increase in $k$ has virtually no effect on expected gross profits (revenues minus wages) despite having a large incremental effect on $\theta k^{\alpha}$. As a result, for low values of $k$, net profits are decreasing in $k$ as the cost of capital increases linearly in $k$. For intermediate values of $k$, utilization rates are sufficiently high that profits are increasing and concave in $k$.

Although expected profits per machine increase with $\sigma$, the partial equilibrium effect on $k$ is ambiguous and depends on the utilization rate. The expected marginal product of capital (i.e. the derivative of gross profits with respect to $k$ ) is given by

$$
M P K=\alpha(1-\Phi(z-\sigma)) k^{\alpha-1} .
$$

The derivative of the marginal product of capital with respect to $\sigma$, holding wages

\footnotetext{
${ }^{6}$ Pindyck (1988) also considers the option value associated with machine shutdown. In his framework, holding constant the option value associated with waiting to invest, an increase in uncertainty raises investment. This result contrasts with that described below.

${ }^{7}$ Equivalently, one can think of $\theta_{i, t}$ as the relative output price for the good produced. The convexity of the profit function with respect to the output price implies that an increase in $\sigma$ raises expected profits.
} 
Figure 4: The Effects of Increased Uncertainty

\section{Expected Profits per Machine}

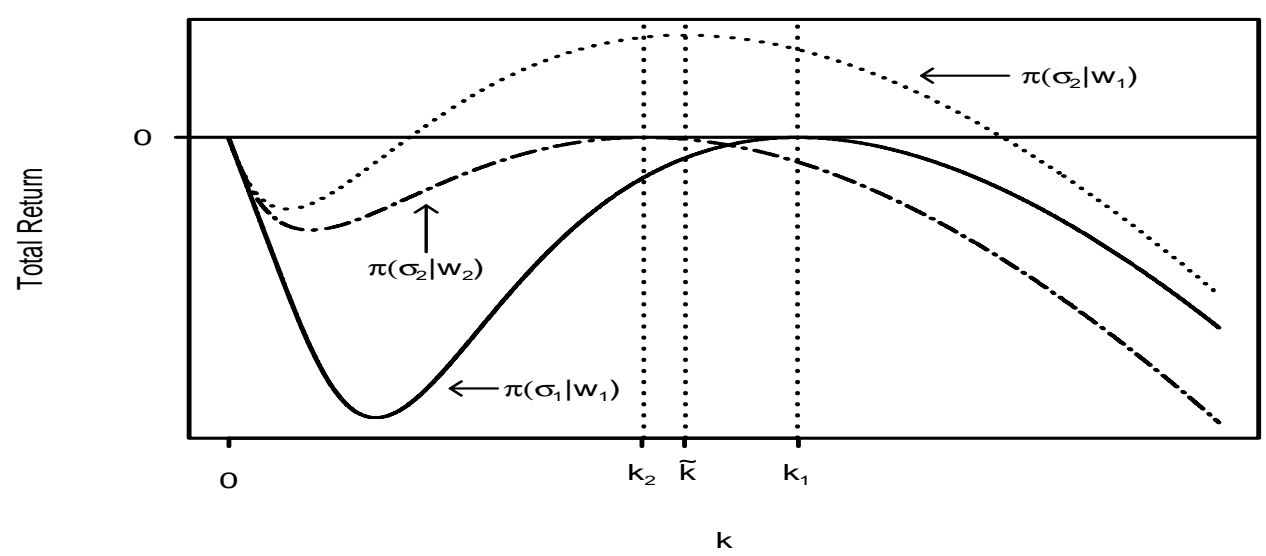

Expected Marginal Product of Machine Capital

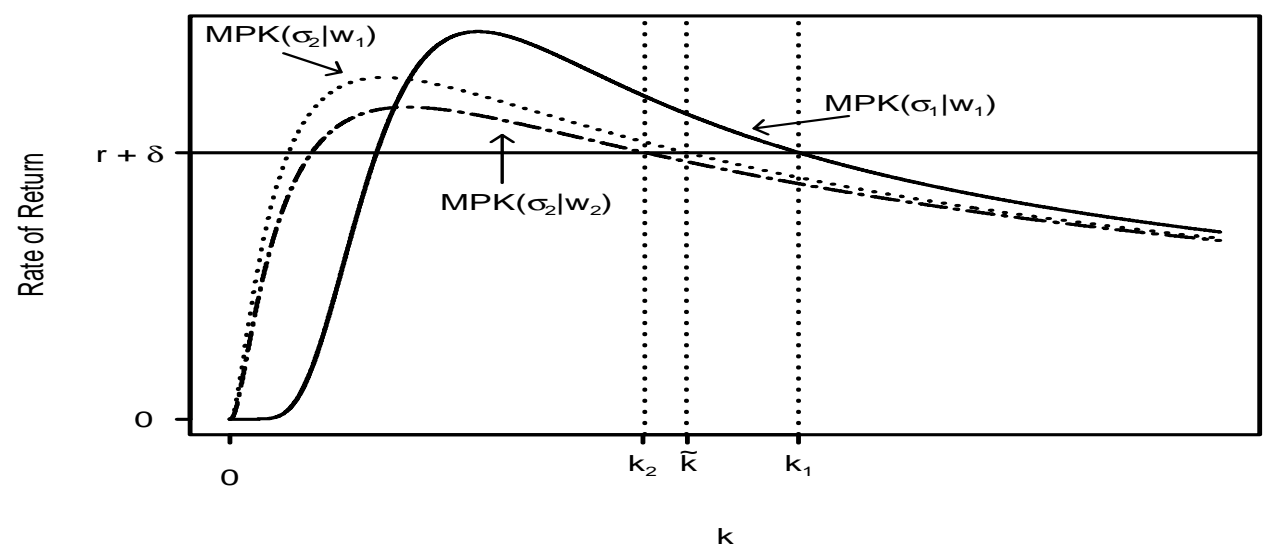

fixed, equals

$$
\frac{\partial \mathrm{MPK}}{\partial \sigma}=\phi(z-\sigma) \alpha k^{\alpha-1} \frac{z}{\sigma}
$$

For $z<0$, that is, at capital utilization rates exceeding $50 \%$, a mean-preserving spread reduces the capacity utilization rate, the marginal product of capital, and $k$. If the capital utilization rate is less than $50 \%$, utilization occurs on the convex portion of $(1-\Phi(z-\sigma))$ and the partial equilibrium effect of an incremental increase in $\sigma$ is to increase, rather than decrease, $k$.

The bottom panel of figure 4 plots the expected marginal product of capital. In equilibrium, the marginal product of capital equals the required return, $r+\delta$; for the 
case of $\sigma=\sigma_{1}$ (solid line), the equilibrium capital-labor ratio equals $k_{1}$. Holding the wage rate fixed at $w_{1}$, an increase in idiosyncratic uncertainty reduces the capacity utilization rate and the marginal product of capital, as shown by the dotted line in the figure. For wage $w_{1}, k$ must fall to $\tilde{k}$ to restore the equality of the marginal product of capital to the required return.

In general equilibrium, higher profits induce new entry. New entry drives up the wage rate, thereby reducing utilization and eroding profits. As shown in the figure, the increase in the wage rate from $w_{1}$ to $w_{2}$ causes a reduction in $k$ to $k_{2}$. The additional investment that occurs through the extensive margin more than offsets any reduction in investment that occurs through the intensive margin and aggregate investment unambiguously rises in response to an increase in idiosyncratic uncertainty.

We now compare this result to that from the Solow vintage model, which we state in the following proposition.

Proposition 4 Define the semi-elasticity of steady-state output with respect to $\sigma$ by $\epsilon \equiv \frac{d \ln y}{d \sigma}$. Then

$$
\epsilon_{\text {putty-clay }}=h(z)<\frac{\sigma}{\alpha}=\epsilon_{\text {Solow }} .
$$

Proof: We need to show that at the equilibrium, $\alpha h(z)<\sigma$, which is established in the proof of proposition 2.

In the Solow vintage model, project-level capital expenditures are irreversibly tied to a specific realization of idiosyncratic productivity $\theta_{i, t}$ but labor can be costlessly reallocated across projects after the realization occurs. A mean-preserving spread causes a reallocation of labor from low productivity to high productivity machines, equalizing the marginal product of labor across machines. This reallocation increases productivity in proportion to $\sigma$ and raises the return to capital, causing investment and output to increase.

In the putty-clay model, labor reallocation is limited to moving workers from machines in the lower tail of the efficiency distribution to new machines, the mean efficiency of which equals average labor productivity. The term $h(z)$ captures the benefits from this reallocation of labor. Specifically, the elasticity of output with respect to $\sigma, \sigma h(z)$, equals the difference between average log-efficiency of machines in use relative to the log-efficiency of all machines

$$
\sigma h(z)=E\left(\ln \left(x_{i}\right) \mid x_{i}>w\right)-E \ln \left(x_{i}\right) .
$$


Table 1: The Expansionary Effect of Increased Uncertainty

\begin{tabular}{cccc}
\hline \hline & \multicolumn{2}{c}{$\begin{array}{c}\text { Semi-elasticity } \\
\text { of Output w.r.t. } \sigma\end{array}$} & $\begin{array}{c}\text { Semi-elasticity } \\
\text { of } k \text { w.r.t. } \sigma \\
\text { Putty-clay }\end{array}$ \\
\hline \multirow{2}{*}{$\begin{array}{c}\text { Solow Vintage } \\
\text { Putty-clay }\end{array}$} & & \\
0.10 & 0.28 & 0.00 & -0.00 \\
0.20 & 0.56 & 0.05 & -0.53 \\
0.30 & 0.83 & 0.24 & -1.52 \\
0.40 & 1.11 & 0.51 & -2.36 \\
0.50 & 1.39 & 0.81 & -3.05 \\
0.75 & 2.08 & 1.58 & -4.48 \\
1.00 & 2.78 & 2.35 & -5.73 \\
& & & \\
\hline
\end{tabular}

Notes: For these computations, $\alpha=0.36$.

At low levels of idiosyncratic uncertainty, the difference between the productivity of machines in use to that of all machines produced is small, and reallocation provides little benefit. As $\sigma$ increases, this gap widens, and the benefit from reallocation rises.

To quantify the effect of variations in $\sigma$ on investment and output, Table 1 shows the semi-elasticities of output with respect to $\sigma$, for different values of $\sigma$, for the putty-clay and Solow vintage models. These results are based on a $36 \%$ capitalshare $(\alpha=0.36)$; no other model parameters enter into the computations. As seen in the table, the output semi-elasticity of the putty-clay model lies well below that of the Solow vintage model. For values of $\sigma$ of 0.2 and smaller, the expansionary effect of increased uncertainty on output in the putty-clay model is trivial. Table 1 also shows $\frac{d \ln k}{d \sigma}$, the semi-elasticity of the capital-labor ratio $k$ with respect to $\sigma$. Investment at the project level is much more sensitive than aggregate investment to variations in $\sigma$. In the putty-clay model, starting from a value of $\sigma$ of 0.2 or greater, an increase in idiosyncratic uncertainty has a quantitatively large negative impact on investment at the machine level. 


\section{The Economy with Growth}

The assumption of zero trend growth simplifies the preceding analysis; however, in order to study the timing of capital goods replacement we need to allow for positive growth. We start by describing and proving existence of a deterministic balanced growth equilibrium. We then analyze the replacement or "endogenous depreciation" of capital goods and relate these findings to the potential for replacement echoes in our model.

\subsection{Equilibrium along the Balanced Growth Path}

Along the balanced growth path, per capita output, consumption, and investment grow at rate $g$, and labor and labor capacity grow at rate $n$. We use lower case letters to indicate steady-state values of variables, normalized by appropriate time trends, and $\tilde{k}$ to indicate the normalized steady-state capital-labor ratio. We define the growth-adjusted discount rate $\tilde{\beta} \equiv \frac{1}{(1+n)(1+g)^{\gamma}} \beta$. Let $z$ denote the difference between the average efficiency of the leading edge technology and the current wage rate in steady state, $z \equiv\left(\ln w-\ln x+\frac{1}{2} \sigma^{2}\right) / \sigma$, and let $z(i)$ denote the difference between the average efficiency of vintage $i$ and the current wage rate $z(i) \equiv z+(i / \sigma) \ln (1+g)$.

On the balanced growth path, the normalized levels of output, consumption, labor, and the wage rate are given by

$$
\begin{gathered}
y=q x \sum_{j=1}^{M}((1+g)(1+n))^{-j}\left(1-\delta_{j}\right)(1-\Phi(z(j)-\sigma)), \\
c=y-\tilde{k} q, \\
l=q \sum_{j=1}^{M}(1+n)^{-j}\left(1-\delta_{j}\right)(1-\Phi(z(j))) . \\
w=\frac{(1+g)^{-j} x \phi(z(j)-\sigma)}{\phi(z(j))}, j=1, \ldots, M .
\end{gathered}
$$

Note that $y / q, c / q, l / q$, and $w$ depend only on the values of $\tilde{k}$ (directly and indirectly through $x=\tilde{k}^{\alpha}$ ) and $z$. The first-order condition for $k$ and the zero-profit condition yield two equations in $z$ and $k$

$$
\begin{aligned}
& \tilde{k}=\alpha \sum_{j=1}^{M} \tilde{\beta}^{j}\left(1-\delta_{j}\right)\{(1-\Phi(z(j)-\sigma)) x\}, \\
& \tilde{k}=\sum_{j=1}^{M} \tilde{\beta}^{j}\left(1-\delta_{j}\right)\left\{(1-\Phi(z(j)-\sigma)) x-(1+g)^{j}(1-\Phi(z(j))) w\right\} .
\end{aligned}
$$


By combining these last three equations, we obtain the balanced growth equilibrium condition for $z$.

As in the no-growth economy, an equilibrium value of $z$ is determined by setting utilization rates so that a weighted average of vintage labor shares equals $1-\alpha$. In the case of positive growth, however, these weights are not fixed constants as in the no-growth case, but instead depend on $z$. As a result, with positive growth one cannot rule out a priori the existence of multiple steady-state values of $z$ without additional assumptions, as stated in the following proposition.

\section{Proposition 5 Let}

$$
v(z(j))=\frac{\tilde{\beta}^{j}\left(1-\delta_{j}\right)(1-\Phi(z(j)-\sigma))}{\sum_{i=1}^{M} \tilde{\beta}^{i}\left(1-\delta_{i}\right)(1-\Phi(z(i)-\sigma))}
$$

define a set of weights such that $\sum_{j=1}^{M} v(z(j))=1$, then there exists at least one steady state value of $z$ that satisfies

$$
(1-\alpha)=\sum_{j=1}^{M} v(z(j)) \frac{h(z(j)-\sigma)}{h(z(j))} .
$$

A sufficient condition for uniqueness of the equilibrium is that the sum $\sum_{j=1}^{M} \tilde{\beta}^{j}(1-$ $\left.\delta_{j}\right)(1-\Phi(z(j)-\sigma))$ be log-concave in $z$.

Proof: Let $\Psi(z) \equiv \sum_{j=1}^{M} \tilde{\beta}^{j}\left(1-\delta_{j}\right)(1-\Phi(z(j)-\sigma)) \frac{h(z(j)-\sigma)}{h(z(j))}$, and $\Gamma(z) \equiv \sum_{j=1}^{M} \tilde{\beta}^{j}(1-$ $\left.\delta_{j}\right)(1-\Phi(z(j)-\sigma))$. Then $\frac{\Psi(z)}{\Gamma(z)}=\sum_{j=1}^{M} v(z(j)) \frac{h(z(j)-\sigma)}{h(z(j))}$ and the balanced growth equilibrium condition may be written

$$
(1-\alpha)=\frac{\Psi(z)}{\Gamma(z)}
$$

Following the proof of result 2, it is straightforward to show that $\lim _{z \rightarrow-\infty} \frac{\Psi(z)}{\Gamma(z)}=0$ and $\lim _{z \rightarrow+\infty} \frac{\Psi(z)}{\Gamma(z)}=1$. Thus, by continuity of $\frac{\Psi(z)}{\Gamma(z)}$, there exists at least one value of $z$ that satisfies the equilibrium condition.

To prove that log-concavity of $\Gamma(z)$ implies uniqueness of the equilibrium we show that $\frac{\partial^{2} \ln \Gamma(z)}{\partial z^{2}}<0$ implies $\frac{\Psi(z)}{\Gamma(z)}$ is monotonically increasing in $z$. Taking derivatives and using the facts that $\Psi^{\prime}(z)=\sigma \Psi(z)+\Gamma^{\prime}(z)$, and $\Gamma^{\prime}(x)=-\sum_{i=1}^{M} \tilde{\beta}^{j}\left(1-\delta_{j}\right) \phi(z(j)-$ $\sigma)$, we obtain

$$
\frac{\partial \frac{\Psi(z)}{\Gamma(z)}}{\partial z}=\sigma \frac{\Psi(z)}{\Gamma(z)}+\left(1-\frac{\Psi(z)}{\Gamma(z)}\right) \frac{\partial \ln \Gamma(z)}{\partial z}
$$


Taking second derivatives we obtain

$$
\frac{\partial^{2} \frac{\Psi(z)}{\Gamma(z)}}{\partial z^{2}}=\left(\sigma-\frac{\Gamma^{\prime}(z)}{\Gamma(z)}\right) \frac{\partial \frac{\Psi(z)}{\Gamma(z)}}{\partial z}+\left(1-\frac{\Psi(z)}{\Gamma(z)}\right) \frac{\partial^{2} \ln \Gamma(z)}{\partial z^{2}}
$$

If $\frac{\partial^{2} \ln \Gamma(z)}{\partial z^{2}}<0$ the second term in this expression is negative. Given $\Gamma^{\prime}(x)<0$ we have $\left(\sigma-\frac{\Gamma^{\prime}(z)}{\Gamma(z)}\right)>0$, so that $\frac{\partial \frac{\Psi(z)}{\Gamma(z)}}{\partial z}<0$ implies that the first term is also negative. Now suppose $\frac{\partial \frac{\Psi\left(z^{*}\right)}{\Gamma\left(z^{*}\right)}}{\partial z}<0$ for some $z^{*}$. Then we have $\frac{\partial^{2} \frac{\Psi\left(z^{*}\right)}{\Gamma\left(z^{*}\right)}}{\partial z^{2}}<0$ implying that $0<\frac{\Psi\left(z^{*}\right)}{\Gamma\left(z^{*}\right)}<1$ and $\frac{\Psi(z)}{\Gamma(z)}$ strictly decreasing on $\left(z^{*}, \infty\right)$, a result which contradicts $\lim _{z \rightarrow+\infty} \frac{\Psi(z)}{\Gamma(z)}=1$.

Note that the possibility of multiple balanced growth equilibria exists only in the case of non-zero trend technological growth. This potential for multiple steady states distinguishes this model from its putty-putty counterpart. Nonetheless, numerical analysis of the model suggests that multiple equilibria occur only in "unusual" regions of the parameter space, for example, when the trend growth rate of technology is extremely large and the value of $\alpha$ lies in a limited range. Further discussion of these issues appears in the appendix. In the following analysis, each of the parameterized versions of the model used possesses a unique steady state.

\subsection{Endogenous Depreciation and Echo Effects}

With positive growth in embodied technology, the real wage rises over time and increasing shares of older vintages of capital become too costly to operate given their labor requirements, with the result that they are mothballed or scrapped. In steady state, the capital utilization rate of capital goods $i$ periods old equals $(1-\Phi(z+(i / \sigma) \ln (1+g)))$. From this formula we see that the two key determinants of the shape and location of the vintage utilization schedule are the long-run growth rate of embodied technology and the degree of idiosyncratic uncertainty.

The primary direct effect of positive trend productivity growth on machine replacement is to shorten the useful life of capital goods. Owing to more rapid growth in real wages, an increase in $g$ speeds up the process of machine replacement, shifting the utilization schedule forward in time. The degree of idiosyncratic uncertainty, on the other hand, mainly affects the shape of the utilization schedule. First, consider the extreme case of no idiosyncratic uncertainty, where all machines of the same vintage are identical. In this case, machines of a given vintage are run at full capacity until the real wage exceeds the vintage's level of productivity, at which time 
Figure 5: Steady-state Capacity Utilization

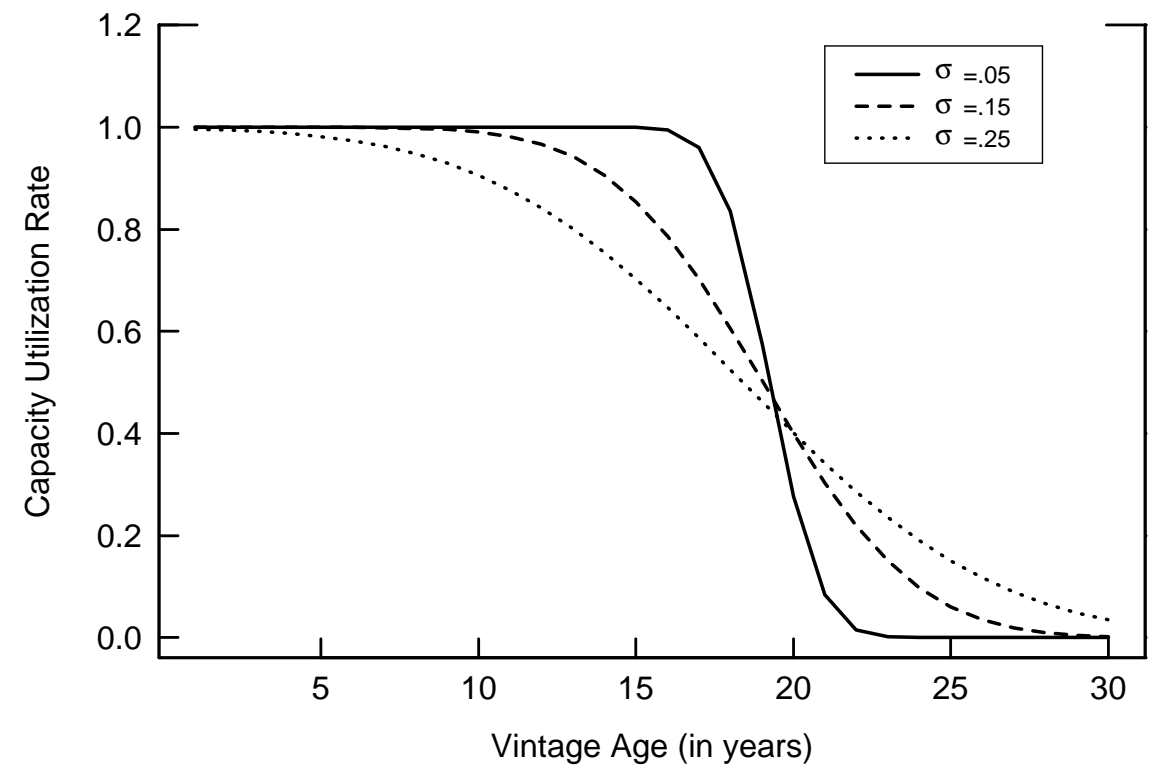

they are retired all together. With a small degree of idiosyncratic uncertainty, the replacement of capital goods follows the basic pattern of the case of no idiosyncratic uncertainty, but relatively inefficient machines are scrapped early and relatively efficient machines are scrapped later. Figure 5 shows steady-state capacity utilization rates across vintages of capital for three values of $\sigma .^{8}$ As $\sigma$ increases, the link between vintage age and machine productivity is weakened, resulting in reduced utilization of recent vintages and increased utilization of older vintages. For low $\sigma$, the depreciation schedule is close to that of the one-hoss-shay, whereas for high $\sigma$, the depreciation schedule begins to resemble exponential decay.

The pattern of scrapping relates to the potential presence of "replacement echoes" of the type studied by Boucekkine et al. (1997), where an initial investment surge leads to recurring spikes in investment as successive vintages are retired. In the context of our putty-clay model, pronounced replacement echoes occur only in the absence of mechanisms which lead to the smoothing of capital goods replacement over time. Specifically, necessary conditions for replacement echoes to exist in our putty-clay model are (i) a low degree of idiosyncratic uncertainty and (ii) a high intertemporal elasticity of consumption.

If the degree of idiosyncratic uncertainty is not sufficiently low, the resulting

\footnotetext{
${ }^{8}$ For the examples shown in figures 5 and 6, we assume there is no "exogenous" capital depreciation, i.e., $\delta=0$.
} 
Figure 6: Replacement Echoes

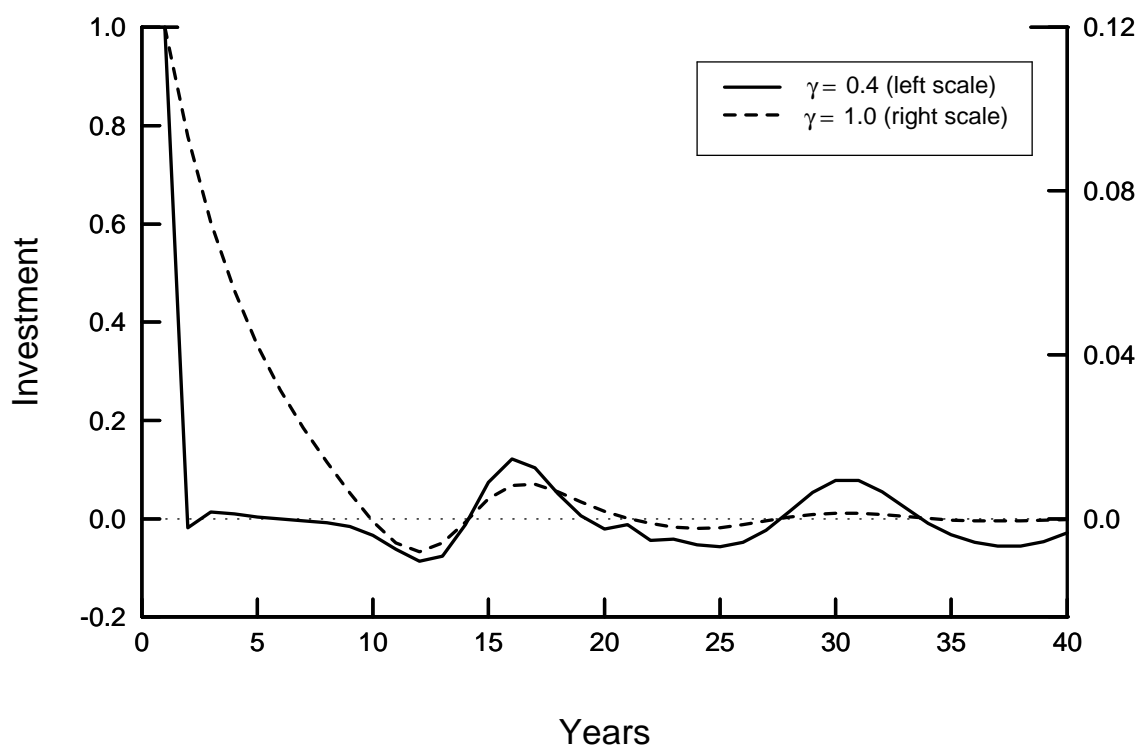

gradually declining utilization schedule shown in figure 5 smooths the process of machine replacement over time and significantly dampens replacement echoes. The need for a high intertemporal elasticity of consumption to generate replacement echoes is demonstrated in figure 6 , which shows the response of aggregate investment (shown as percentage point deviations from steady state) to an unanticipated shock that destroys a portion of the stock of the most recent vintage of capital. This artificial example generates the requisite initial spike in investment. The solid line shows the response when $\sigma=0.1$ and the intertemporal elasticity of substitution for consumption is $2.5(\gamma=0.4)$. With these preferences, the desire for consumption smoothing is relatively weak. The shock elicits a sharp initial rise in investment and a relatively strong and persistent pattern of replacement echoes. The dashed line shows the simulated outcome with an intertemporal elasticity of substitution of unity (log preferences). In response to the shock, households' desire for a smooth consumption path causes investment to initially only rise by a small amount and remain above steady state for an extended period as the capital stock is gradually rebuilt. One small replacement echo occurs, but no further echo materializes. 


\section{Conclusion}

In this paper, we investigate the microeconomic and aggregate implications for investment and output that result from assuming ex post fixity of capital-labor ratios in a putty-clay model of capital accumulation. The model that we develop provides a set of microeconomic foundations for the analysis of investment under uncertainty, capacity utilization, and machine retirement in a general equilibrium framework. Aggregation over heterogeneous capital goods results in a well-defined aggregate production function that preserves the putty-clay microeconomic structure and is easily characterized in terms of hazard rates of the standard normal distribution.

The analysis yields a number of interesting results. First, we show that under the assumptions of the model, the aggregate production function takes an intermediate form between that of Cobb-Douglas and Leontief, depending on the degree of idiosyncratic uncertainty. Second, we find that an increase in idiosyncratic uncertainty typically reduces investment at the micro level but raises aggregate investment. Finally, we find that two factors are key to the existence of replacement echoes: the degree of idiosyncratic uncertainty and the intertemporal elasticity of substitution of consumption.

An important question in macroeconomics is how the economy responds to factor price variation induced by changes in tax structure or embodied technological change. The putty-clay framework developed in this paper is well suited for studying the dynamic implications of factor price movements in the presence of irreversible investment decisions reflected in the ex post fixity of capital-labor ratios. In a companion piece (Gilchrist and Williams 1998), we study the dynamic properties of the one-sector growth model specified in this paper. Our model may be easily extended to a more general multi-sector or multi-country setting. It may also provide a useful framework for studying the transition dynamics of developing economies that are adopting new technology through the process of capital accumulation. 


\section{References}

Abel, Andrew, "Optimal Investment under Uncertainty," American Economic Review, 1983, 73, 228-33.

Ando, Albert, Franco Modigliani, Robert Rasche, and Stephen Turnovsky, "On the Role of Expectations of Price and Technological Change in an Investment Function," International Economic Review, 1974, 15, 384-414.

Atkeson, Andrew and Patrick J. Kehoe, "Putty-Clay Capital and Energy," August 1994. NBER Working Paper No. 4833.

Bagnoli, M. and T. Bergstom, "Log-concave probability and its applications.," Mimeo, Univ. of Michigan 1989.

Benhabib, Jess and Aldo Rustichini, "Vintage Capital, Investment and Growth," Journal of Economic Theory, 1991, 55, 323-339.

and _ _ "A Vintage Capital Model of Investment and Growth: Theory and Evidence," in R. Becker, M. Boldrin, R. W. Jones, and W. Thompson, eds., General Equilibrium, Growth, and Trade II: The Legacy of Lionel W. McKenzie, New York: Academic Press, 1993, pp. 248-301.

Bernanke, Ben, "Irreversibility, Uncertainty, and Cyclical Investment," Quarterly Journal of Economics, 1983, 98, 85-106.

Bischoff, Charles W., "The Effect of Alternative Lag Distributions," in G. Fromm, ed., Tax Incentives and Capital Spending, Washington, D.C.: The Brookings Institution, 1971, chapter 3, pp. 61-130.

Boucekkine, Raouf, Marc Germain, and Omar Licandro, "Replacement Echoes in the Vintage Capital Growth Model," Journal of Economic Theory, $1997,74,333-48$.

Calvo, Guillermo A., "Optimal Growth in a Putty-Clay Model," Econometrica, $1976,44,867-878$.

Cass, David and Joseph E. Stiglitz, "The Implications of Alternative Saving and Expectations Hypotheses for Choices of Technique and Patterns of Growth," Journal of Political Economy, 1969, 77, 586-627. 
Cooley, Thomas F., Jeremy Greenwood, and Mehmet Yorukoglu, "The Replacement Problem," 1994. Institute for Empirical Macroeconomics Discussion Paper 95.

Cooper, Russell and John Haltiwanger, "The Macroeconomic Implications of Machine Replacement: Theory and Evidence," American Economic Review, 1993, 83, 360-382.

Gilchrist, Simon and John C. Williams, "Putty-Clay and Investment: A Business Cycle Analysis," 1998. Finance and Economics Discussion Series, paper 1998-30, Board of Governors of the Federal Reserve.

Hartman, Richard, "The Effects of Price and Cost Uncertainty on Investment," Journal of Economic Theory, 1972, 5, 285-266.

Houthakker, H.S., "The Pareto Distribution and the Cobb-Douglas Production Function in Activity Analysis," Review of Economic Studies, 1953, 60, 27-31.

Johansen, Leif, "Substitution versus Fixed Production Coefficients in the Theory of Economic Growth: A Synthesis," Econometrica, 1959, 27, 157-176.

Johnson, Norman L., Samuel Kotz, and N. Balakrishnan, Continuous Univariate Distributions, Volume 1, Second Edition, New York: John Wiley \& Sons, 1994.

Leahy, John V. and Toni M. Whited, "The Effect of Uncertainty on Investment: Some Stylized Facts," Journal of Money, Credit and Banking, 1996, 29, 64-83.

Phelps, Edmund S., "Substitution, Fixed Proportions, Growth and Distribution," International Economic Review, 1963, 4, 265-288.

Pindyck, Robert S., "Irreversible Investment, Capacity Choice, and the Value of the Firm," American Economic Review, 1988, 78, 969-985.

_ _ " "Irreversibility, Uncertainty, and Investment," Journal of Economic Literature, 1991, 29, 1110-1148.

Sheshinski, E., "Balanced Growth and Stability in the Johansen Vintage Model," Review of Economic Studies, 1967, 34, 239-248. 
Solow, R.M., "Substitution and Fixed Proportions in the Theory of Capital," Review of Economic Studies, 1962, 29, 207-218. 


\section{Appendix}

\section{Results regarding the hazard rate of the standard normal distribu- tion used for proofs in the text:}

In the following, let $h(x)$ denote the hazard rate for the standard normal distribution, $h(x) \equiv \phi(x) /(1-\Phi(x))$. From the definition of the hazard rate, we know $h(x)=$ $E(y \mid y>x), y \sim N(0,1)$, which implies that $h(x)>0$ and $h(x)>x$, for all $x$.

Result 1: $h(x)$ is monotonically increasing in $x$, with $\lim _{x \rightarrow-\infty} h^{\prime}(x)=0$ and $\lim _{x \rightarrow+\infty} h^{\prime}(x)=1$.

Proof Taking the derivative of $h(x)$, we have $h^{\prime}(x)=h(x)(h(x)-x)>0$, where the inequality follows directly from the definition of the hazard rate of the standard normal. To establish the lower limit of $h^{\prime}(x)$, first note that $\lim _{x \rightarrow-\infty} h(x)=0$. Then, $\lim _{x \rightarrow-\infty} h^{\prime}(x)=-\lim _{x \rightarrow-\infty} x h(x)=-\lim _{x \rightarrow-\infty} x \phi(x)=0$, where the final equality results from applying l'Hopital's rule. To establish the upper limit, note that application of l'Hopital's rule yields $\lim _{x \rightarrow+\infty} h^{\prime}(x)=\lim _{x \rightarrow+\infty} h(x) / x$. Applying l'Hopital's rule yields $\lim _{x \rightarrow+\infty} \frac{h(x)}{x}=\lim _{x \rightarrow+\infty}\left(1+\frac{1}{x^{2}}\right)=1$, which establishes the result.

Result 2: $h(x)$ is log-concave, that is, $\ln (h(x))$ is strictly concave in $x .^{9}$

Proof To prove log-concavity, we need to show that $\frac{\partial \ln (h(x))}{\partial x}=\frac{h^{\prime}(x)}{h(x)}$ is decreasing in $x$, which is true if $h^{\prime}(x)<1$. Consider $h^{\prime \prime}(x)$

$$
h^{\prime \prime}(x)=h(x)\left[(h(x)-x)^{2}+\left(h^{\prime}(x)-1\right)\right]
$$

which is strictly positive if $h^{\prime}(x) \geq 1$. Suppose $h^{\prime}\left(x^{*}\right) \geq 1$ for some $x^{*}$. Then, $h^{\prime}(x)$ is increasing at $x^{*}$, implying $h^{\prime}(x)>1$ and $h^{\prime \prime}(x)>0$ for all $x>x^{*}$, a result which contradicts $\lim _{x \rightarrow+\infty} h^{\prime}(x)=1$, established in Result 1. Alternatively, it is straightforward to show that for the standard normal distribution $\operatorname{Var}(y \mid y>x)=$ $1-h^{\prime}(x)$, which implies $h^{\prime}(x)<1$ for all $x$.

Result 3: $h(x)$ is strictly convex in $x$.

Proof Let $g(x)=\left[(h(x)-x)^{2}+\left(h^{\prime}(x)-1\right)\right]$; then, $h^{\prime \prime}(x)>0$ iff $g(x)>0$. Given the limiting results established above, it is straightforward to obtain $\lim _{x \rightarrow-\infty} g(x)=\infty$

\footnotetext{
${ }^{9}$ Bagnoli and Bergstom (1989) provide some results on properties of log-concave distribution functions, including a proof that the reliability function $1-\Phi(x)$ is log-concave. We require however that the hazard rate itself be log-concave.
} 
and $\lim _{z \rightarrow+\infty} g(x)=0$. Now, consider $g^{\prime}(x)$

$$
g^{\prime}(x)=2(h(x)-x)\left(h^{\prime}(x)-1\right)+h(x) g(x)
$$

which is strictly negative if $g(x) \leq 0$. Suppose $g\left(x^{*}\right) \leq 0$ for some $x^{*}$, implying that $g^{\prime}\left(x^{*}\right)<0$. This then implies that $g(x)<0$ and $g^{\prime}(x)<0$ for all $x>x^{*}$, a result which contradicts $\lim _{x \rightarrow+\infty} g(x)=0$.

Result 4: For a given constant $c>0, \frac{h(x-c)}{h(x)}$ is monotonically increasing in $x$ with $\lim _{x \rightarrow-\infty} \frac{h(x-c)}{h(x)}=0$ and $\lim _{x \rightarrow+\infty} \frac{h(x-c)}{h(x)}=1$.

Proof To prove that $h(x-c) / h(x)$ is monotonically increasing in $x$ we compute

$$
\frac{\partial(h(x-c) / h(x))}{\partial x}=\frac{h(x-c)}{h(x)}\{h(x-c)-(x-c)-(h(x)-x)\} .
$$

which is positive if the term in brackets is positive. We therefore need to show that $h(y)-y>h(x)-x$ for $y<x$ which is true if $h^{\prime}(x)<1$, i.e., if $h(x)$ is $\log$ concave, which is proven in Result 2 above. To show the lower limit we note that $\frac{h(x-c)}{h(x)}=\left(e^{\left(2 x c-c^{2}\right) / 2}\right)\left(\frac{1-\Phi(x)}{1-\Phi(x-c)}\right)$ and take limits. To establish the upper limit, we use the mean value theorem to obtain $h(x)=h(x-c)+c^{\prime}\left(x^{*}\right)$ for $x-c<x^{*}<x$. We then use $x^{*}<x$ and $h^{\prime \prime}(x)>0$ to obtain the bounds $1>\frac{h(x-c)}{h(x)}>1-\frac{h^{\prime}(x)}{h(x)} c$. Result 1 implies $\lim _{x \rightarrow+\infty} \frac{h^{\prime}(x)}{h(x)}=0$, which establishes the result.

Result 5: For a given constant $c>0, c(h(x-c)-(x-c))(h(x)-x)>h(x-$ c) $-h(x)+c$.

Proof Let

$$
f(x)=c[\omega(x-c) \omega(x)]+[\omega(x)-\omega(x-c)] .
$$

where $\omega(x)=h(x)-x>0$. Taking limits we obtain $\lim _{x \rightarrow-\infty} \omega(x)=\infty$, $\lim _{x \rightarrow+\infty} \omega(x)=0$, implying $\lim _{x \rightarrow-\infty} f(x)=\infty$ and $\lim _{x \rightarrow+\infty} f(x)=0 . \quad$ Taking derivatives we have: $\omega^{\prime}(x)=h^{\prime}(x)-1<0$ and $\omega^{\prime \prime}(x)=h^{\prime \prime}(x)>0$. Since $\omega(x)$ is decreasing and strictly convex in $z$, we have $\omega^{\prime}(x)<\omega^{\prime}(x-c)$ and

$$
f^{\prime}(x)=c\left[\omega^{\prime}(x-c) \omega(x)+\omega(x-c) \omega^{\prime}(x)\right]+\left[\omega^{\prime}(x)-\omega^{\prime}(x-c)\right]<0 .
$$

Given that $\lim _{x \rightarrow-\infty} f(x)=\infty$ and $\lim _{x \rightarrow+\infty} f(x)=0, f^{\prime}(x)<0$ implies $f(x)>0$ for all $x$. 


\section{Multiple Equilibria in the Economy with Growth}

We first provide some analysis of the conditions needed to guarantee the log-concavity of $\Gamma(z) \equiv \sum_{j=1}^{M} \tilde{\beta}^{j}\left(1-\delta_{j}\right)(1-\Phi(z(j)-\sigma))$ and hence a unique steady-state equilibrium. We then consider what set of parameter values may lead to multiple equilibria.

To begin, consider the function $\Gamma^{\prime \prime}(z) \Gamma(z)-\Gamma^{\prime}(z)^{2}$ which, if negative, guarantees log-concavity of $\Gamma(z)$ and hence uniqueness of the equilibrium. We know that the reliability function $(1-\Phi(x))$ is log-concave and $\Gamma(z)$ is the weighted sum of such functions, which, while not sufficient to guarantee log-concavity, suggests that it may be difficult to produce circumstances under which it does not obtain. Let $\omega_{j}=\tilde{\beta}^{j}\left(1-\delta_{j}\right)$ and $z_{j}=z(j)-\sigma$. After some manipulation we obtain

$$
\begin{aligned}
\Gamma^{\prime \prime}(z) \Gamma(z)-\Gamma^{\prime}(z)^{2}= & \sum_{j=1}^{M} \sum_{k=1}^{M} \omega_{j} \omega_{k} \phi\left(z_{j}\right)\left[\left(z_{j}\right)\left(1-\Phi\left(z_{k}\right)-\phi\left(z_{k}\right)\right]\right. \\
= & \sum_{j=1}^{M} \sum_{k=1}^{M} \omega_{j} \omega_{k} \phi\left(z_{j}\right) \phi\left(z_{k}\right)\left(\frac{z_{j}}{h\left(z_{k}\right)}-1\right) \\
= & \sum_{j=1}^{M} \sum_{k=1}^{M} \omega_{j} \omega_{k} \phi\left(z_{j}\right) \phi\left(z_{k}\right)\left(\frac{z_{k}}{h\left(z_{k}\right)}-1\right) \\
& +\sum_{j=1}^{M} \sum_{k=1}^{M} \omega_{j} \omega_{k} \phi\left(z_{j}\right) \phi\left(z_{k}\right)\left(\frac{z_{j}-z_{k}}{h\left(z_{k}\right)}\right) .
\end{aligned}
$$

The first term in this expression is clearly negative. The second term may be positive if for some $j, k$ we have large productivity differentials between vintages $j$ and $k$.

Because $z_{j}$ is linearly increasing in machine age, a large productivity differential is likely to occur when vintage $j$ is substantially older and less productive than vintage $\mathrm{k}$. In this case, however, the contribution of this term to the sum is relatively small owing to discounting, both explicitly through the term $\tilde{\beta}^{j}\left(1-\delta_{j}\right)$ and implicitly through a low value of $\phi\left(z_{j}\right)$. Furthermore, for any positive term $\left(z_{j}-z_{k}\right) / h\left(z_{k}\right)>0$ there is an equally weighted negative term $\left(z_{k}-z_{j}\right) / h\left(z_{j}\right)<0$. This suggests that only under extreme parameterizations can we have large productivity differentials that yield positive values of any magnitude for

$$
\omega_{j} \omega_{k} \phi\left(z_{j}\right) \phi\left(z_{k}\right)\left(\frac{\left(z_{j}-z_{k}\right)}{h\left(z_{k}\right)}+\frac{\left(z_{k}-z_{j}\right)}{h\left(z_{j}\right)}\right),
$$

the weighted sum of these components. In turn, these positive values must be large enough to offset the negative sum in the first component of $\Gamma^{\prime \prime}(z) \Gamma(z)-\Gamma^{\prime}(z)^{2}$. 
Note that log-concavity of $\Gamma(z)$ is a sufficient, not necessary, condition for a unique steady-state value of $z$. Indeed, it is not necessary that $\Psi(z) / \Gamma(z)$ be monotonically increasing, as long as it crosses $(1-\alpha)$ only once. Numerical experiments suggest that multiple equilibria only occur when both the trend productivity growth rate is exorbitantly high, so that productivity differentials across vintages are large, and when discounting through the real interest rate and depreciation is very low. For example, we obtain multiple equilibria in the model when $\sigma=0.1$, $\delta_{j}=0, j=1, \ldots, M, \gamma=0.1, g=0.6$ (60\% per annum), and $\beta=0.999$. These parameter values imply that $z_{2}-z_{1}>5$. Relatively small adjustments in parameter values result in the number of equilibria to collapsing to one. We have found no evidence of multiple equilibria using more conventional parameterizations that would typically characterize the capital accumulation process in a general equilibrium model calibrated based on empirical moments of industrialized economies. 